\title{
The Efficient Liability Sharing Factor for Environmental Disasters: Lessons for Optimal Insurance Regulation"
}

\author{
Marcel Boyer ${ }^{\mathrm{a}}$ and Donatella Porrini ${ }^{\mathrm{b}}$ \\ ${ }^{a}$ Department of Economics, Université de Montréal, C.P. 6128, succursale Centre-ville, Montreal QC, \\ Canada $\mathrm{H} 3 \mathrm{C} 3 \mathrm{~J} 7$. \\ E-mail: Marcel.Boyer@cirano.qc.ca \\ ${ }^{b}$ Facoltà di Economia Ecotekne, Università di Lecce, Via per Monteroni, Lecce 73100, Italy. \\ E-mail: d.porrini@economia.unile.it
}

Using a structural model of the interactions between governments, firms and insurance companies, we characterize the distortions in environmental liability sharing between firms and insurance companies that the imperfect implementation of government policies implies. These distortions stem from three factors: the presence of moral hazard, the noncongruence between firms/insurers' objectives and social welfare, and the courts' imperfect assessment of safety care levels exerted by firms. We characterize cases where the efficient liability sharing factor is above or below its full information perfect implementation level. We derive comparative statics results indicating how sensitive the liability sharing factor is to changes in parameters (parameters that underlie the firm profit level and volatility, the cost of safety care, the monitoring cost, the social cost of public funds, the effectiveness of care in reducing the probability of accident) that are relevant for the characterization of optimal policies (liability sharing, safety care standards) toward environmental protection or the prevention of industrial accidents. We derive policy implications regarding environmental disaster insurance policies.

The Geneva Papers (2008) 33, 337-362. doi:10.1057/gpp.2008.9

Keywords: liability sharing; environmental insurance; safety care; moral hazard; principal-agent

Jel classification: D82; G32; K13; K32; Q28

\section{Introduction}

From an economic perspective, assigning liability to polluters can be seen as an instrument to internalize environmental damage, thus providing proper compensation for victims and adequate decontamination of polluted sites. ${ }^{1}$ Moreover, such an

\footnotetext{
* We are grateful to anonymous referees and to the participants in the Joint Seminar of The Geneva Association and EALE (Lecce, June 2007) for their comments on a previous draft of this paper, as well as to participants in The Stony Brook Law and Economics Workshop (Long Island, July 2005) and in the 15th Annual Meeting of the American Law and Economics Association (New York, May 2005), whose suggestions led to the current paper. We remain of course solely responsible for the content and shortcomings of this paper.

${ }^{1}$ See Baumol and Oates (1988); Cropper and Oates (1992).
} 
assignment of liability provides potentially liable parties with incentives to opt for careful behavior: an ex post liability system induces ex ante investments in care. ${ }^{2}$

This paper deals with the role that financial and insurance instruments can play within a system of liability assignment. More precisely it deals with the role of the legal liability framework in fostering the financial internalization of environmental damages through a liability sharing factor.

In the first part, we review the limits of the traditional liability insurance in the context of the present U.S. and EC liability systems. We then outline a second class of instruments, namely financial responsibility, which induces the firm to identify ex ante the financial resources to be allocated to damage prevention and compensation.

In the second part, through a structural model of the interactions between governments, firms and insurers, we characterize the distortions in environmental liability sharing between firms and insurers that the imperfect implementation of government policies implies. In particular, we consider the three factors that generate these distortions: the presence of moral hazard, the non-congruence between firms/ insurers' objectives and social welfare, and the courts' imperfect assessment of safety care levels exerted by firms.

We characterize cases where the efficient liability sharing factor is above or below its full information perfect implementation level. Moreover, we derive comparative statics results indicating how sensitive the liability sharing factor is to changes in parameters that underlie the firm profit level and volatility, the cost of safety care, the monitoring cost, the social cost of public funds, as well as the effectiveness of care in reducing the probability of accident.

Finally, we sketch some policy implications regarding environmental disaster insurance.

\section{The role of insurance companies in internalizing environmental damages}

\section{Insurance companies as "sharing actors": economic advantages}

Insurance companies could play a role in the internalization of environmental damage in the context of the assignment of liability. Particularly, the instruments that will be described in the next paragraphs, both traditional liability coverage and financial guarantees, involve the insurance companies together with liable firms through a kind of "sharing factor." The first question we address is what economic advantages can be derived from this involvement and then what is the optimal "sharing factor."

From an economic point of view, the role of insurance instruments may provide a number of advantages. First, liability insurance policies and financial responsibility ensure that the expected costs related to environmental risks are recorded in the firm's financial statements. If any new investments imply possible future environmental costs, such costs, as relevant, are included in the firm's decisions. Other benefits result from the fact that, since a policy or a financial guarantee are purchased from insurance

\footnotetext{
${ }^{2}$ The connection between ex post liability effects and ex ante prevention behavior is stressed by the law and economics literature: see Calabresi (1970); Shavell (1987).
} 
companies, a contract relation is established, by which the latter are keen on protecting their investments through the monitoring of the production and safety activities of their corporate customers.

An insurance company as the principal is encouraged to monitor the environmental risk-prevention activity of its corporate customers; the agent firm, in turn, pays to the principal, through the premium, the cost related with these risks and is therefore encouraged to adopt preventive measures to reduce the risks and, as a result, the insurance's cost. It has been demonstrated in the economic literature that, with perfect information available, the bank or insurer may induce the firm to adopt effective precautionary measures. ${ }^{3}$ Even more so, in the case of financial responsibility, the firm itself should demonstrate its ability to show financial guarantees to cover the damage resulting from a possible environmental accident. Perfectly informed "financial guarantors" force the firm to take into account the whole extent of the damage ex ante and to pay a premium adjusted to the granted financial guarantees: also in this case a perfect internalization of the damage resulting from environmental accidents is achieved. $^{4}$

Monitoring is even more important if information asymmetries affect the insurance companies. The firm, in fact, pays an interest rate as a cost for the guarantee that also includes a sort of premium for the risk of liability extension to the lenders, and feels therefore less exposed to the risk and less encouraged to adopt preventive measures, and thus adopts moral hazard behavior. The solution may call for a careful monitoring by the insurance companies that provides an incentive both to the firms to adopt a high level of prevention and to the insurance companies in terms of recovery, through the contract, of a share of the amount disbursed to indemnify the victims. $^{5}$

Besides moral hazard issues, adverse selection issues may also arise: in this case, the characteristics of the firm's production activity are not perfectly known to the insurance companies. If this kind of information asymmetries occurs, and if the insurance company charges a high interest rate taking into account the risks linked to liability extension, the mean quality of the firms applying for guarantees may decline, causing a subsequent adverse selection phenomenon. ${ }^{6}$

Thus, on one hand, insurance companies are encouraged to ensure that the firms adopt an adequate level of preventive measures; on the other hand, the firms are encouraged to adopt preventive measures to appear at their best upon entering into the agreements. In this respect, the "financial guarantors" may provide a remedy to information asymmetries issues and, in particular, to moral hazard-related issues through monitoring and to adverse selection-related issues through proper contract design and appropriate guarantee costs, offering lower cost guarantees to the firms that make less risky choices from the environmental viewpoint and that provide for prevention schemes.

\footnotetext{
${ }^{3}$ For a demonstration: see Segerson and Tietenberg (1992).

${ }^{4}$ For an economic analysis of the financial responsibility instrument: see Feess and Hege (2000).

${ }^{5}$ See Pitchford (1995); Boyer and Laffont (1997).

${ }^{6}$ See Heyes (1996).
} 
340

Let us now analyze in details the two kinds of instruments through which the insurance companies can be "sharing actors" in the internalization of environmental damage: liability insurance policies and financial responsibility tools.

\section{Traditional liability insurance}

In the last two decades, many legal systems, both in common law and in civil law countries, have developed environmental liability assignment systems. The most common regimes for assignment of liability follow the so-called polluter pays principle. The principle can be defined as "economic," in that it provides for charging the cost of the damage to the party that is liable for the accident rather than to society at large through, for example, a public fund. ${ }^{7}$

To achieve the internalization of damage due to an environmental accident, a crucial role can be played by the insurance sector through the supply of coverage for damages. The advantage of a liability insurance instrument is basically that "the availability of liability insurance increases the welfare of risk-averse injurers because it protects them from risk and ameliorates the problems that they would otherwise take excessive care or be discouraged from engaging in desirable activities. Moreover, the availability of liability insurance does not necessarily dilute injurers' incentives to reduce risk, and where it does do that, the dilution of incentives will be moderate, for policies that would substantially increase risks would be so expensive that they would not be attractive for purchase." 8

Generally environmental insurance has peculiar features: the supply of environmental insurance is based on the calculation of premiums but the losses deriving from an environmental accident damage may be difficult to define and measure and, moreover, the probability of an accident of a given severity level may be difficult to determine. Insurance companies must also face the problem of asymmetric information, namely adverse selection and moral hazard. Problems of adverse selection come from the difficulties to observe the risk characteristics of individual insured parties and consequently to discriminate between different risk categories. Problems of moral hazard come from the difficulties in monitoring the preventive behavior of the insured individuals.

The problems just mentioned have been extensively discussed in economic contributions: ${ }^{9}$ they explain why environmental liability coverage is provided only through very specific policies. ${ }^{10}$ But also the legal framework characterizing different countries has important effects on the development of such insurance policies.

The U.S. experience with environmental issues provides an excellent example in several respects. The issue of environmental liability in that country fully emerged in

\footnotetext{
7 "Even legal scholars argue that the polluter pays principle is originally an economic principle which seems to state that the costs of pollution clean-up should not be borne by the taxpayer, but by the person responsible for the pollution" (Faure and Grimeaud (2000, p. 21)).

${ }^{8}$ See Shavell (2003, p. 38).

${ }^{9}$ See Freeman and Kunreuther (1997); Laffont and Martimort (2001).

${ }^{10}$ For example in Italy a Pool, that is, a voluntary association of insurance companies, manages the environmental liability insurance, named $R C$ inquinamento.
} 
the 1980s, when several pollution cases were recorded and, at the same time, an increased number of small enterprises entered risky sectors. ${ }^{11}$ In 1980 , the Congress passed the Comprehensive Environmental Response, Compensation and Liability Act (CERCLA) and a whole range of amendments in the following years, in order to cope with the "decontamination" of polluted sites by recovering the clean-up costs from the liable parties and by creating a public fund, the Superfund.

This system provides for the coverage of damage on the specified sites, ${ }^{12}$ resulting in particular from the contamination produced by dangerous activities, as well as the damage to natural resources. The liable parties were considered to include the past owners and the operators of the affected sites, as well as the current owners and operators, the generators of dangerous polluting materials stored on those sites, and the carriers of such materials. All these parties are retroactively, strictly and jointly liable. Therefore each one may be held responsible for the whole amount of the damage.

In the legal framework defined by the CERCLA liability assignment system, some problems of insurability emerged, in particular the following two: the involvement of many liable parties, the so-called Potentially Responsible Parties (PRPs); and the retroactivity that made the liability assignment unpredictable by the insurance companies.

These problems contributed to the very small supply of insurance coverage at the beginning by the U.S. insurance companies. ${ }^{13}$ Generally the insurance sector in the 1980s was characterized by a deep crisis linked with the uncertainty deriving from the application of tort law. ${ }^{14}$ In the environmental case in particular, a massive phenomenon of litigation characterized the years following the enactment of CERCLA and a huge amount of resources was devoted to cover legal expenses rather that to provide for environmental decontamination. "Moreover, in coincidence with the very confused and questionable development of case law on CERCLA liabilities, a crisis struck the environmental insurance market and very little pollution coverage has been available on the U.S. marketplace until recent years." 15 Nowadays in the U.S., environmental liability policies are widely supplied by insurance companies, given that courts decisions have become more predictable and that a complex and strictly enforced regulatory system has been developed in recent years.

Regarding the European experience, the Directive on "Environmental Liability with Regard to the Prevention and Remedying of Environmental Damage" 16 states that "The prevention and remedying of environmental damage should be implemented through the furtherance of the 'polluter pays' principle,' as indicated in the Treaty and in line with the principle of sustainable development. The fundamental principle of this Directive should therefore be that an operator whose activity has caused the

\footnotetext{
${ }^{11}$ See Ringleb and Wiggins (1990).

12 The Superfund allows decontaminating the sites included in a national list, the National Priority List (NPL), with money being primarily collected from taxes on oil and oil-derived products.

13 See Abraham (1988).

14 See Priest (1987).

15 See Monti (2001, p. 69).

${ }^{16}$ European Parliament and Council (2004).
} 
environmental damage or the imminent threat of such damage is to be held financially liable, in order to induce operators to adopt measures and develop practices to minimise the risks of environmental damage so that their exposure to financial liabilities is reduced" (point (2), Directive 2004/35/CE).

The European system for the assignment of liability provides strict liability for the damage caused by dangerous activities and fault-based liability for damage caused to biodiversity by non-dangerous activities; the Community legislator decided to include the damage to biodiversity resulting from activities that do no involve the use of noxious substances, but the system adopted in this case provides for liability assignment to occur on the ground of an at least thoughtless behavior. ${ }^{17}$

"Member States should take measures to encourage the use by operators of any appropriate insurance or other forms of financial security and the development of financial security instruments and markets in order to provide effective cover for financial obligations under this Directive" (point (27), Directive 2004/35/CE). The EC legislator provides that the development of the insurance system should reduce the number of cases where reclaiming of the contaminated sites is impossible due to firm insolvency, the so-called orphan sites, and the existence of an effective insurance system should allow firms to protect themselves against environmental risks by including insurance premiums among their production costs.

So despite the difficulties that led to the poor diffusion of insurance instruments within individual European countries in the past, ${ }^{18}$ the EC legislator strongly recommended the development of an effective insurance system offering a full range of insurance policies against environmental risks and, in particular, against any damage caused by production activities to natural resources, linked to the Europe-wide liability system to cover damage in case of environmental accidents. In this direction, the European system partially tries to solve the problems of insurability that had characterized the U.S. system, providing no joint liability and no retroactivity. Moreover, some important limits to the environmental liability regime will make the liability assignment system more predictable: liability is only effective when polluters can be identified, a causal connection must be shown and damage results must be quantifiable given a classification of dangerous activities and an identification of protected biodiversity.

\section{Financial responsibility for environmental damages}

After considering in the previous section the traditional environmental liability insurance, we introduce financial responsibility as an instrument that provides for the potential polluters to demonstrate ex ante that their financial resources are adequate for the restoration of potential environmental damage they may cause. In one of its practical applications, financial responsibility is a pre-condition for production

\footnotetext{
${ }^{17}$ In this respect: "While defining liability in such a way may be considered fairer than employing strict liability across the board, it is not clear exactly how this definition will influence the number of clean-ups or transaction costs that result" (Stone McGuigan (2000, p. 26)).

${ }^{18}$ Faure and Skogh (1992) provide a number of statistics demonstrating the poor diffusion of this kind of insurance in Europe, in particular for accidents caused by nuclear power plants.
} 
activities in risky sectors where firms are authorized only if they can demonstrate an appropriate financial or insurance coverage for future obligations resulting from the assignment of environmental liability.

From an economic point of view, financial responsibility is an instrument to internalize environmental damage with the involvement of the insurance companies when they are called to provide the appropriate guarantees.

According to Boyd, financial responsibility requires guarantees such as: letters of credit and surety bonds; cash accounts and certificates of deposit; and self-insurance and corporate guarantee. ${ }^{19}$ In the following, we will illustrate some practical applications in the U.S., where these instruments are widely developed, and we will have a look at the EC legal provisions that will determine the development of these instruments in European countries.

The above-mentioned financial responsibility instruments are widely applied in the United States since the 1980s within the framework of the liability assignment system for environmental damage. In particular, we can mention the following application: the Resource Conservation and Recovery Act (RCRA) provides for the owners and operators in the oil and oil-derived products storage sector to have an adequate capital level in order to be authorized to carry out their activity. ${ }^{20}$

The same principle was confirmed in the 1990s, for example in the Oil Pollution Act (33 USC. \$2716 of 1990). Several further cases of regulation of the financial insurance related to important federal laws on the environment are recorded: financial responsibility is provided for by CERCLA, by the Safe Drinking Water Act (SDWA), by the Outer Continental Shelf Lands Act (OCSLA), and by the Surface Mining Control and Reclamation Act (SMCRA). ${ }^{21}$ Given these provisions in the U.S. law, a market for insurance coverage has developed to provide a variety of financial instruments tailored to individual firms and regulatory needs.

This kind of instrument, widely enforced in the U.S., has a corresponding importance in the European law but a relatively small diffusion. In fact, in paragraph 4.9 of the White Paper on Environmental Liability, ${ }^{22}$ on "Financial security," we can find the statement: "When looking at the insurance market - insurance being one of the possible ways of having financial security, alongside, among others, bank guarantees, internal reserves or sector-wise pooling systems - it appears that coverage

${ }^{19}$ Boyd (2002). Letters of credit and surety bonds are purchased from banks or insurance companies: they require paying a third-party beneficiary, often the government, under some circumstances as the failure of the purchaser to perform certain obligations. Cash accounts and certificates of deposit place cash or some other forms of interest-bearing security into accounts that are made payable to or assigned to a regulatory authority. Self-insurance is made by the companies with relatively deep pockets to satisfy coverage requirements by demonstrating sufficient financial strength. A corporate guarantee allows another firm, such as a parent corporation, to satisfy the coverage requirement and financial guarantors must themselves agree to cover the liabilities of the firm.

${ }^{20}$ In the case of "hazardous waste", the 1976 Resource Conservation and Recovery Act (RCRA) and the 1980 Comprehensive Environmental Response Act (CERCLA) provide for the companies that "treat, store, dispose, or transport hazardous waste" to demonstrate adequate financial guarantees for thirdparty damage, through an insurance or a proof of financial coverage.

21 See Boyd (2003).

22 COM (2000, 66 final). 
of environmental damage risks is still relatively undeveloped, but there is clear progress being made in parts of the financial markets specialising in this area." And the enforcement of such instruments seems to be delayed in time, according to the statement that "Member States shall take measures to encourage the development of financial security instruments and markets by the appropriate economic and financial operators, including financial mechanisms in case of insolvency, with the aim of enabling operators to use financial guarantees to cover their responsibilities under this Directive" (art. 14, Directive 2004/35/CE).

Generally all these different instruments of financial responsibility are considered as an alternative but also a complementary instrument to the traditional liability insurance, offering some advantages also in facing the problem of judgment proof. ${ }^{23}$ Moreover, the financial responsibility instruments have many other advantages: first of all, they provide for an effective compensation; secondly, they partially solve some problems related to information asymmetries that characterize the application of liability insurance; finally, they can induce the involvement of the capital market in the environmental damage internalization. ${ }^{24}$ Moreover, a role can be played by financial responsibility instruments with respect to problems of insurability that characterize the application of traditional liability insurance.

In the previous paragraph, we have seen as a problem of insurability that liability insurance provides for the transfer of the accident risk to the insurance companies with the problem of quantifying the damage, something that is particularly difficult, especially in the environmental sector. On the other hand, based on financial responsibility, the risk remains within the firm that places a real deposit, which can be claimed to cover the environmental damage, however always within the limits of the insured amount. The quantification of the environmental damage, in this case, is the basis for an ex ante calculation of the due deposit that should be such as to provide an adequate level of financial resources to be used in case of accident. If the damage then exceeds the deposit, the firm is liable for the whole amount of the damage, eventually with judgment proof problems.

Finally, a further benefit that adds up to the above and results from the enforcement of financial responsibility is that this instrument looks like a market-oriented solution. Through financial responsibility, risk-shares may be brought to the capital market: investors may subscribe these shares and thus create a guarantee in favor of companies operating in risky sectors. Therefore, financial responsibility instruments as a solution for the internalization of environmental damage can be considered to fall within the set of market-oriented instruments constituting the new frontier in the area of environmental policy choice.

Given the advantages of the insurance instruments that emerged in the analysis in the previous paragraphs, a very important role can be played by the insurance companies providing both traditional liability coverage and financial guarantees. In this sense, we will present in the next part of the paper a model to identify the efficient liability sharing factor between liable parties and insurance companies. The results of

\footnotetext{
${ }^{23}$ See Shavell (1986). See also Boyer and Porrini (2002).

${ }^{24}$ On this last specific point: see Tyran and Zweifel (1993).
} 
the model are intended to make clear which could be the involvement of the insurance companies or banks trying to solve the issue of internalizing environmental damages.

\section{The basic issues}

In the next part of the paper we will formalize a model to analyze a sharing factor between liable parties and insurance companies, using a framework that is a form of "extended principal-agent liability," under which insurance companies have an incentive to properly identify and monitor risky firms. Referring to the law and economics literature, principal-agent liability relates to cases where instead of a single actor as injurer, harm is caused by an individual or a firm that is under the control or supervision of someone else. Principal-agent schemes are applied to analyze cases in which liability is extended from the person that directly caused the damage to a party that is in some sense related to that person. ${ }^{25}$

The law and economics literature represents principal-agent liability as a framework where maximizing agents choose their preventive care level under the monitoring activities of some principal. ${ }^{26}$ Usually in these models there is no room for considering how the agent's prevention decision may be influenced by factors other than the maximization hypothesis and the principal's influence. ${ }^{27}$ Instead in this paper, we widen the traditional framework by adopting the legislator's point of view which, in these cases, is to determine what mix of liability to impose on the principal and the agent in order to maximize the social welfare function. ${ }^{28}$

By sharing liability with insurance companies, the legislator will delegate part of its control upon the firms' preventive behavior by inducing them to internalize environmental damage. In fact, under a liability sharing system, the insurance company is responsible for a fixed part (percentage) of the damage caused and is called upon to influence the firms' environmental prevention activities through different forms of monitoring or incentive insurance contracts.

However, the principal-agent relationship between the insurance and the firm is only part of the complex network of relationships that characterizes the business environment of a firm whose activities give rise to a probability of environmental disaster. Other important parts are governments and courts that play also a role in providing incentives for preventive environmental care by monitoring firms' activities. So the problem of liability sharing involves also regulatory bodies, firms and courts.

\footnotetext{
${ }^{25}$ This is the so-called "secondary" or "vicarious" liability, such as that of the parents who are deemed liable for damage caused by their children, or the employer who is deemed liable for the damage caused by the activities of its employees. See Sykes (1984); Kornhauser (1982).

${ }^{26}$ Polinsky (2003).

${ }^{27}$ Daughety and Reinganum (2003) proposed to widen the standard law and economics literature framework by assuming that market and the tort system interact to affect the decision about prevention care level with reference to product liability. In particular, their analysis includes an endogenously determined fixed-cost component to prevention that comes from the characteristics of the output market, the relevant litigation costs, a representation of victims as consumers, a group of consumers or third parties, and a variety of imperfectly competitive market structures.

28 The same approach was followed in Boyer and Porrini (2006).
} 
346

The model will consider a first relationship between firms and insurance companies implemented by the above-described instrument of financial responsibility by which insurance companies and banks are called upon to provide financial guarantees for firms that operate in risky sectors. Informational asymmetries are present in this relationship and a monitoring role can be played by the financial institutions regarding the prevention care activities implemented by firms.

The second relationship is between firms and the government/legislator that determines a recommended level of safety and sets the rule to share liability between the firm and the financial institution. In the model, the sharing rule takes into account the incentives towards the optimal level of prevention in a framework that is again characterized by the presence of informational asymmetries about the prevention decisions of the firms.

Finally, the third relationship is between firms and courts that are called upon to decide if and when firms are liable in choosing a level of prevention that is lower than the level recommended by government. Also insurance companies may have an interest in suing firms that are (or appear to be) guilty of insufficient preventive action, with the intent of recovering from them their part of the shared burden. ${ }^{29}$

The behaviors of the four actors, government, insurance companies, firms, and courts, will be limited in the model in the following ways. There is limited liability of firms that are judgement proof; there is a limited capacity of governments to intervene; there is a limited power of the court system to search and find all the facts relevant to a judgement; finally there is asymmetric information between the actors (government, firm, insurance company, court), whose decisions and behavior have an impact on the observed probability of environmental accidents.

\section{The model}

The model we develop here is closely based on the model we developed in Boyer and Porrini $^{30}$ with two important changes: we introduce an "insurance premium" to be paid by the firm to the insurer for the latter's payments in case of an accident and we characterize the Nash equilibrium of the "asymmetric information game" being played between the firm and the insurance company regarding the former's choice of prevention program and the latter's choice of monitoring strategy.

As mentioned before, we consider that the probability of an environmental accident depends in a real sense on the actions and constraints (information constraints, legal constraints, and bounded rationality) of four actors or stakeholders that are the government, the firm, the insurer, and the court. It therefore results from the interactions between those actors, whose interests will not in general be fully congruent.

${ }^{29}$ This paper will not explicitly address the issue of the comparison between ex ante and ex post regulations. The role of the courts in evaluating (ex post) the firm's behavior is connected to the command-andcontrol standards set by ex ante regulation. In this sense, the role of providing incentives for preventive care by the means of monitoring activities is shared between regulatory agencies and the courts (Boyer and Porrini (2001, 2004)).

${ }^{30}$ Boyer and Porrini (2006). 
More precisely, the government aims to maximize social welfare and, with this objective in mind, imposes a strict liability-sharing formula between the insurance company and the firm: the firm will be strictly responsible for $\alpha$ percent of the damages and the insurance company for $(1-\alpha)$ percent. The social value of such a shared strict liability rule comes from our assumption that the government is necessarily the payer of last resort and that there is a positive social cost of public funds. The government also sets the safety care standard $s$ for the firm but cannot directly enforce it given that the information on the level of prevention activities is typically private to the firm. This modeling strategy will be more fully justified below.

The firm chooses a program of self-protection, namely a level of care activities $q$, which determines the decreasing and convex probability $p(q)\left[p^{\prime}(q)<0, p^{\prime \prime}(q)<0\right]$ of occurrence of an environmental accident with an assumed exogenous loss $L$.

The insurance company, which we assume for simplicity reasons to be the financier making possible the operations of the firm, is allowed to sue its client firm for breach of contract in order to recuperate, if the firm-chosen care $q$ is found to be less than the government-determined standard $s$, part or all of the payment it made under the strict liability rule, that is, part or all of its payment $(1-\alpha) L$. Allowing the insurer to sue the firm for breach of contract, that is, for presumed insufficient level of care, serves as a mean for the insurer to induce the firm to choose a proper level of care. The strict liability rule is imposed and the right to sue is granted by the social welfare maximizing government under the belief that insurers are potentially more efficient supervisors of the firm's safety care program than bureaucrats in a governmental department of environmental protection and industrial safety. Indeed, in United States v. Fleet Factors Corp. (901 F. 2d 1550 (11th Cir. 1990), cert. Denied, 498 U.S. 1046 (1991)), ${ }^{31}$ the judge wrote:

Our ruling today should encourage potential creditors to investigate thoroughly the waste treatment systems and policies of potential debtors. If the treatment systems seem inadequate, the risk of CERCLA liability will be weighed into the terms of the loan agreement. Creditors, therefore, will incur no greater risk than they bargained for and debtors, aware that inadequate hazardous waste treatment will have a significant adverse impact on their loan terms, will have powerful incentives to improve their handling of hazardous wastes.

Similarly, creditors' awareness that they are potentially liable under CERCLA will encourage them to monitor the hazardous waste treatment systems and policies of their debtors and insist upon compliance with acceptable treatment standards as a prerequisite to continued and future financial support. Once a secured creditor's involvement with a facility becomes sufficiently broad that it can anticipate losing its exemption from CERCLA liability, it will have a strong incentive to address hazardous waste problems at the facility rather than studiously avoiding the investigation and amelioration of the hazard.... The scope of the secured creditor exemption is not determined whether the creditor's

\footnotetext{
${ }^{31}$ For a discussion of the Fleet Factors case and other cases, see Boyer and Laffont $(1996,1997)$ and Boyer and Porrini (2006).
} 
activity was taken to protect its security interest. What is relevant is the nature and extent of the creditor's involvement with the facility, not its motive. To hold otherwise would enable secured creditors to take indifferent and irresponsible actions towards their debtors' hazardous wastes with impunity by incanting that they were protecting their security interests. Congress did not intend CERCLA to sanction such abdication of responsibility.

If the insurer sues the firm (it will do so with probability $v$ in our model), then the case is litigated in court. The court, suffering from the same asymmetric information as the government and insurer but with superior power to investigate the safety behavior of the firm, hears the evidence and decides on the breach of contract, that is, whether $q$ is less than $s$ or not. We represent the court decision-making process under incomplete information by assuming that the firm is found guilty of insufficient care with a reduced-form probability $P(q, s)$ that is decreasing and convex in $q$ and increasing in $s\left[P_{q}(q, s)<0, P_{q q}(q, s)>0\right.$, and $\left.P_{s}(q, s)>0\right]$. Hence, both type I errors (finding an innocent firm guilty) and type II errors (finding a guilty firm innocent) are possible. $^{32}$

We assume that the firm needs a loan of $K$ from the insurer acting as financier to operate a risky project: the project generates net benefits (profits) $\pi_{1}$ with probability $\mu$ and $\pi_{2}$ with probability $1-\mu$ (with $\pi_{2}>\pi_{1}$ ). The realized level of profit is also typically private information of the firm: we model it that way to represent the adverse selection problem present in the interactions between the four stakeholders. Hence, the loan is a contract, under which the firm must repay the principal and interest while failing to do so would trigger bankruptcy procedures: the amount to be paid by the firm to the financier is $(1+r) K$, where $r$ is the (exogenous) competitive interest rate for the type of firm, loan category, and/or industry considered, plus an "insurance/liability premium" given by $(1-\alpha) p(s) L$. We assume quite realistically that this liability premium is based on the observed legal level of care $s$ rather than on the unobserved level of care $q$, which is not directly observable.

We solve the above problem as a three-stage game to characterize subgame perfect equilibria. In stage 1 , the government chooses $\alpha$ and $s$ to maximize a social welfare function that we characterize below. In stage 2 , the firm and the insurer negotiate a contract by which the insurer as financier makes possible the operation of the firm and is paid $Z Z=(1+r) K+(1-\alpha) p(s) L$, and choose their respective control variable $q$ and $v$. We consider two variants of this choice process. In model variant $\mathrm{S}$ ( $\mathrm{S}$ for Stackelberg), the insurer announces and commits to its choice of $v^{33}$ at cost $C(v)$ while the firm, observing $v$, chooses its safety care level $q$ at cost $Q(q)$. We characterize the resulting Stackelberg Equilibrium in $(v, q)$. In model $\mathrm{N}$ ( $\mathrm{N}$ for $\mathrm{Nash})$, the insurer

\footnotetext{
${ }^{32}$ See Boyer and Porrini (2008) for a discussion of how court efficiency in reducing type I and type II errors affects liability, safety care and probability of accident.

${ }^{33} \mathrm{We}$ assume that the insurer commits to its choice of $v$. One may think that if the insurer builds up a suing capacity, for instance through a specific inside group of lawyers, then it is bound to let them work full time and therefore sue firms with the implied probability $v$.
} 
announces its choice of $v$ and the firm chooses the safety care level $q$ simultaneously at costs $C(v)$ and $Q(q)$, respectively. We characterize the resulting Nash Equilibrium in $(v, q)$.

In stage 3, all actors observe whether an accident occurs or not (profits remain unobserved). If an accident occurs, the strict liability rule applies: the insurer is responsible for covering $(1-\alpha) L$ and the firm for covering $\alpha L$. The insurer sues the firm with probability $v$. If sued, the firm incurs legal defense costs $C_{F}$. The court is then called into play and finds the firm guilty of negligence with probability $P(q, s)$. If convicted of negligence, the firm makes the additional payment $(1-\alpha) L$ if possible and otherwise goes bankrupt, in which case the insurer seizes the firm's net assets, equal in value to $\max \left\{0, \pi_{1}-\alpha L-Z Z-Q(q)-C_{F}\right\}$.

The problem is solved recursively. The main contribution of the paper is in the sensitivity analysis of changes in profitability, cost and efficiency of care, cost of suing, and social cost of public funds on the social welfare maximizing liability sharing formula and standard of care. The sensitivity analysis is performed in the penultimate section.

\section{The third stage (given the previously determined values of $\boldsymbol{\alpha}, \boldsymbol{s}, \boldsymbol{v}$, and $\boldsymbol{q}$ )}

The total expected profit of the insurer $E \Pi_{I}$ can be written as follows, where $Z Z=(1+r) K+(1-\alpha) p(s) L$ :

$$
\begin{aligned}
& E \Pi_{I}\left(v, q, \alpha, s ; K, r, \pi_{1}, \pi_{2}, \mu\right)=Z Z-C(v) \\
& \quad-p(q)[(1-v)+v(1-P(q, s))](1-\alpha) L \\
& \quad-p(q) v P(q, s)(1-\mu)[0] \\
& \quad-p(q) v P(q, s) \mu[(1-\alpha) L \\
& \left.\quad-\max \left\{0, \pi_{1}-\alpha L-Z Z-Q(q)-C_{F}\right\}\right]
\end{aligned}
$$

The first term $Z Z-C(v)$ is the profit, gross of loan $K$, in the absence of an accident. If an accident occurs, then the insurer will incur the full cost of its liability share, namely $(1-\alpha) L$, in two situations: first, if it does not sue the firm and second, if the firm is found not guilty by the court (second term: $-p(q)[(1-v)+$ $v(1-P(q, s))](1-\alpha) L)$; if the insurer sues the firm and the firm is found guilty, then the insurer can recover its full share of the damages when the firm has realized the high level of profit, in which case the insurer's cost is zero (third term: $-p(q) \nu P(q, s)(1-\mu)[0]$, as we assume for simplicity that if profit is high, that is, if the project is ex post very valuable, the firm can pay the full amount of damages); finally, if the insurer sues the firm and the firm is found guilty, then it may be able to recover part of its (strict liability) payments if the firm has realized the low level of profit, in which case either the firm can pay part of the insurer's costs or not, depending on whether $\pi_{1}-\alpha L-Z Z-Q(q)-C_{F}$ is positive or not (fourth term: $\left.-p(q) v P(q, s) \mu\left[(1-\alpha) L-\max \left\{0 . \pi_{1}-\alpha L-Z Z-Q(q)-C_{F}\right\}\right]\right)$. 
Similarly, the total expected profit of the firm can be written as follows, where $E \pi=\mu \pi_{1}+(1-\mu) \pi_{2}$ :

$$
\begin{aligned}
& E \Pi_{F}\left(v, q, \alpha, s ; K, r, \pi_{1}, \pi_{2}, \mu\right)=E \pi-Q(q)-Z Z \\
& \quad-p(q)(1-v)\left[(1-\mu) \alpha L+\mu \min \left\{\alpha L, \pi_{1}-Q(q)-Z Z\right\}\right] \\
& \quad-p(q) v(1-P(q, s))\left[(1-\mu)\left(\alpha L+C_{F}\right)\right. \\
& \left.\quad+\mu \min \left\{\alpha L+C_{F}, \pi_{1}-Q(q)-C_{F}-Z Z\right\}\right] \\
& \quad-p(q) v P(q, s)\left[(1-\mu)\left(L+C_{F}\right)\right. \\
& \left.\quad+\mu \max \left\{0, \pi_{1}-Q(q)-C_{F}-Z Z\right\}\right]
\end{aligned}
$$

In light of our interpretation of the different terms of the expected profit of the insurer, each term of the above expression is self-explanatory.

The second stage (Model $\mathbf{S}$ - Stackelberg) (given the previously determined values of $\boldsymbol{\alpha}$ and $\boldsymbol{s}$ )

The firm chooses $q$ satisfying

$$
\frac{\partial E \Pi_{F}}{\partial q}=0
$$

giving rise to the best reply function $q\left(v \mid \alpha, s ; K, r, \pi_{1}, \pi_{2}, \mu, L, C_{F}, C_{B}\right)$ to the choice of $v$ made by the insurer, given $\alpha$ and $s$ set by the government. Knowing this best reply function of the firm, the insurer chooses $v$ satisfying

$$
\frac{\mathrm{d} E \Pi_{B}}{\mathrm{~d} v}=0
$$

taking full account of the best reply function of the firm. The solution to the last two conditions gives us the second-stage Sequential or Stackelberg equilibrium values, which can be expressed as functions of the government-determined variables $\alpha$ and $s$, namely:

$$
\begin{aligned}
& v^{S *}\left(\alpha, s ; K, r, \pi_{1}, \pi_{2}, \mu, L, C_{F}, C_{B}\right) \\
& q^{S *}\left(\alpha, s ; K, r, \pi_{1}, \pi_{2}, \mu, L, C_{F}, C_{B}\right)
\end{aligned}
$$

The second stage (Model $N$ - Nash) (given the previously determined values of $\boldsymbol{\alpha}, \boldsymbol{s}$ )

The firm chooses $q$ satisfying

$$
\frac{\partial E \Pi_{F}}{\partial q}=0
$$

giving rise to the best reply function $q\left(v \mid \alpha, s ; K, r, \pi_{1}, \pi_{2}, \mu, L, C_{F}, C_{B}\right)$ to the choice of $v$ made by the insurer, given $\alpha$ and $s$ set by the government. The insurer chooses $v$ satisfying

$$
\frac{\partial E \Pi_{B}}{\partial v}=0
$$


giving rise to the best reply function $v\left(q \mid \alpha, s ; K, r, \pi_{1}, \pi_{2}, \mu, L, C_{F}, C_{B}\right)$ to the choice of $q$ made by the firm, given $\alpha$ and $s$ set by the government. The solution to the last two conditions gives us the second-stage Simultaneous or Nash equilibrium values, which can be expressed as functions of the government-determined variables $\alpha$ and $s$, namely:

$$
\begin{aligned}
& v^{N *}\left(\alpha, s ; K, r, \pi_{1}, \pi_{2}, \mu, L, C_{F}, C_{B}\right) \\
& q^{N *}\left(\alpha, s ; K, r, \pi_{1}, \pi_{2}, \mu, L, C_{F}, C_{B}\right)
\end{aligned}
$$

\section{The first stage}

We consider, again for simplification reasons without loss of generality, that the determination of the liability sharing formula involves a "political economy" cost $A(\alpha)$ if the government wants to implement a formula away from the most acceptable formula from a social or political standpoint (assumed below to correspond to an equal liability sharing: $\alpha=50$ percent). ${ }^{34}$

The social welfare function $\operatorname{SWF}(\alpha, s)$ is given by (where $W$ is the social value of the firm's project or activities and $\lambda$ is the social cost of public funds representing the cost of government financing either through taxation or public debt):

$$
\begin{aligned}
& S W F(\alpha, s)=\left[W-p\left(q^{*}\right) L-Q\left(q^{*}\right)-C\left(v^{*}\right)-A(\alpha)\right] \\
& \quad-\lambda p\left(q^{*}\right)\left(1-v^{*}\right) \mu \max \left\{0, \alpha L-\left(\pi_{1}-Z Z-Q\left(q^{*}\right)\right)\right\} \\
& \quad-\lambda p\left(q^{*}\right) v^{*}\left(1-P\left(q^{*}, s\right)\right) \\
& \quad \times \mu \max \left\{0, \alpha L-\left(\pi_{1}-Z Z-C_{F}-Q\left(q^{*}\right)\right)\right\} \\
& \quad-\lambda p\left(q^{*}\right) v^{*} P\left(q^{*}, s\right) \mu \max \{0, \alpha L \\
& \left.\quad-\max \left\{0, \pi_{1}-Z Z-C_{F}-Q\left(q^{*}\right)\right\}\right\}
\end{aligned}
$$

The first term of the $S W F$ function, $\left[W-p\left(q^{*}\right) L-Q\left(q^{*}\right)-C\left(v^{*}\right)-A(\alpha)\right]$, is simply the net value of the firm/project absent an accident: the social value $W$ minus the expected cost of an accident, the cost of care, the cost of maintaining the legal suing capacity, and the political economy cost of moving away from the most acceptable liability sharing formula. The second term, namely $-\lambda p\left(q^{*}\right)\left(1-v^{*}\right)$ $\mu \max \left\{0, \alpha L-\left(\pi_{1}-Z Z-Q\left(q^{*}\right)\right)\right\}$, represents in expected terms the social cost of payments by the government if an accident occurs and the insurer is not suing the firm but the firm may not be able to pay its own share of the damages, in which case the government must one way or another pay for the remaining damages, cleanup costs or compensation costs. The third term, namely $-\lambda p\left(q^{*}\right) v^{*}\left(1-P\left(q^{*}, s\right)\right) \mu$ max $\left\{0, \alpha L-\left(\pi_{1}-Z Z-C_{F}-Q\left(q^{*}\right)\right)\right\}$, represents in expected terms the social cost of payments by the government if an accident occurs, the insurer is suing the firm (the firm then suffers a legal defense cost $C_{F}$ ), and the firm is found not guilty but may not be able to pay its share of the damages of the accident. Finally, the fourth and last term, $-\lambda p\left(q^{*}\right) v^{*} P\left(q^{*}, s\right) \mu \max \left\{0, \alpha L-\max \left(0, \pi_{1}-Z Z-C_{F}-Q\left(q^{*}\right)\right)\right\}$, represents in expected terms the social cost of disbursements by the government if an accident occurs, the

\footnotetext{
${ }^{34}$ This assumption will make the interpretation of the chosen $\alpha$ easier by determining a reference point $\alpha=50$ percent. It plays no other role.
} 
financier is suing the firm, and the firm is found guilty of negligence but may not be able to pay the full damages of the accident. To understand the form of this last term, one must realize that the government will be a payer only if the firm cannot even repay its own share of the damages, in which case the firm cannot reimburse the insurer and the government will pay the residual value $\alpha L-\left\{\pi_{1}-Z Z-C_{F}-Q\left(q^{*}\right)\right\}$; however, if the firm can reimburse a part of the insurer's cost when found guilty of insufficient care, that is, when $\alpha L-\max \left\{0, \pi_{1}-Z Z-C_{F}-Q\left(q^{*}\right)\right\}<0$, then the government would pay nothing under the rule of strict liability of the firm and the insurer.

The government maximizes this $S W F$ function with respect to $\alpha$ and $s$, considering the social cost of public funds and the effect of its decision on the choice of $v$ and $q$ in the second stage and the resulting probability of accident, expected damages, and total costs of realizing the project, that is, of allowing the firm to operate.

Clearly, the general solution of such a program and the full characterization of the three-stage Stackelberg and Nash equilibria is a formidable task. Rather than deriving such a general characterization, which at best will be seriously restricted by a set of conditional statements, we will consider a simplified example that contains and respects all the relevant characteristics of the problem at hand.

\section{A simplified example}

We consider the following functions that satisfy the general characteristics of the functions we introduced above.

$$
\begin{gathered}
p(q) \equiv p_{0}+\left(p_{M}-p_{0}\right)\left(1-\mathrm{e}^{-\eta q}\right) \\
\begin{cases}=p_{0} & \text { if } q=0 \\
\rightarrow p_{M} & \text { if } q \text { becomes very large }\end{cases} \\
P(q, s) \equiv \mathrm{e}^{-\delta(q / s)} \begin{cases}=1, & \text { if } q=0 \\
=\mathrm{e}^{-\delta}, & \text { if } q=s(P(s, s)=0.5 \text { if } \delta=\ln 2) \\
\rightarrow 0, & \text { as } q \text { becomes very large }\end{cases} \\
Q(q) \equiv z q^{b}
\end{gathered}
$$

where $b>1$ and $z$ is a positive parameter.

$$
\begin{gathered}
C(v) \equiv B v^{n} \\
A(\alpha) \equiv A(\alpha-0.5)^{a}
\end{gathered}
$$

We consider the following parameter values: $\pi_{1}=1,000, \pi_{2}=5,000, \mu=0.2, K=75$, $r=0.10, p_{0}=0.4, p_{M}=0.05, \delta=\ln (2), z=10, b=1.2, L=4,000, \eta=0.2, C_{F}=0, B=1, n=2$, $\lambda=0.3, A=25, a=2$. Given those values, we obtain the following first-best (full information) solution: ${ }^{35}$

$$
a_{F B}=0.5, \quad q_{F B}=13.17, \quad p\left(q_{F B}\right)=0.075
$$

${ }^{35}$ All numerical results were obtained through MATLAB programming. We are grateful to Peuo Tuon of CIRANO for her assistance in this matter. 
and the following asymmetric information solutions, our base case scenarios, from which sensitivity analysis will be performed in the next section.

\section{Base case S.1 (Model S-Stackelberg)}

Hence, in the Stackelberg equilibrium with asymmetric information, we have $\alpha<\alpha_{F B}$, that is, the liability share of the firm is lower than in the first-best solution. Moreover, $q<q_{F B}$ and $p(q)>p\left(q_{F B}\right)$, that is, the firm exerts less care in preventing accidents and therefore the probability of accidents increases (Table 1).

\section{Base case N.1 (Model N-Nash)}

Hence, in the Nash equilibrium with asymmetric information, we have $\alpha<\alpha_{F B}$, that is, the liability share of the firm is lower than in the first-best solution. Moreover, $q<q_{F B}$ and $p(q)>p\left(q_{F B}\right)$, that is, the firm exerts less care in preventing an accident and therefore the probability of accident increases. Compared with the Stackelberg equilibrium, we obtain a slightly lower liability share for the firm ( 0.35658 vs. 0.37387$)$, a higher standard for care, a higher probability of suing, a slightly higher level of care and therefore a slightly lower probability of accident (0.081578 vs. 0.82377$)$, and a higher probability of conviction. All those adjustments translate into a slightly lower $S W F$ in the Nash equilibrium. The differences are mainly due to the complex but different ways in which the asymmetric information is controlled under the two different timing assumptions in stage 2, either sequential in s or simultaneous in $\mathrm{N}$ (Table 2).

\section{Sensitivity analysis}

We consider in this section the impact on the first-best and second-best liability sharing $\alpha$, standard of care $s$, probability of suing $v$, exerted care level $q$, probability of accident $p(q)$, and probability of conviction if sued $P(q, s)$, of changes in the profitability of the firm's project or activities $(\mu)$, the cost $(z)$ of care activities, the efficiency $(\eta)$ of care in reducing the probability of accident, the cost of suing $(B)$, and the social cost of public funds $(\lambda)$. In the following tables, the bold line corresponds to the base case scenario.

Table 1 Base case scenario (S.1)

\begin{tabular}{cccccc}
\hline$\alpha$ & $s$ & $v$ & $q$ & $p(q)$ & $P(q, s)$ \\
\hline 0.37 & 17.336 & 0.894 & 11.900 & 0.082 & 0.621 \\
\hline
\end{tabular}

Table 2 Base case scenario (N.1)

\begin{tabular}{lccccc}
\hline$\alpha$ & $s$ & $v$ & $q$ & $p(q)$ & $P(q, s)$ \\
\hline 0.36 & 22.910 & 0.913 & 12.027 & 0.082 & 0.695 \\
\hline
\end{tabular}




\section{Model S (Stackelberg)}

Case S.2: Sensitivity to changes in the profitability of the firm

The parameters are same as in the above Base Case (S.1) except for the parameter representing the profitability of the firm, namely $\mu \in[0.1,0.3]$ (Table 3 ).

Hence, a reduction in the profitability of the firm (higher $\mu$ ) generates a reduced liability for the firm and an increased standard of care; an increase in the probability of suing; a reduction in the level of care and a rise in the probability of accident; and a rise in the probability of conviction. The main factor explaining those results is that a lower profitability of the firm implies a more frequent reliance on government funds to cover the cost of an accident. Hence, to alleviate the effect of the social cost of public funds on the value of SWF, the insurer is made increasingly liable, that is, the legal compulsory level of insurance for environmental disasters is increased. Although the level of suing increases, the firm tends to lower its care activities given its reduced liability. The increases in $s$ combined with the reduction in $q$ increases the probability of conviction.

Case S.3: Sensitivity to changes in the cost of care

The parameters are same as in Base Case (S.1) except for the parameter representing the cost of care activities, namely $z \in[5,20]$. We obtain the following results in Table 4 , where the first-best solution changes with the changes in parameter $z$.

Hence, a higher cost of care changes the first-best values (a reduced care $q$ and therefore an increased probability of accident $p(q)$ ) and generates: a reduced liability for the firm but the standard of care goes up and down; an increase in the probability

Table 3 Variable profitability $\mu$ (S.2)

\begin{tabular}{lcccccc}
\hline$\mu$ & $\alpha$ & $s$ & $v$ & $q$ & $p(q)$ & $P(q, s)$ \\
\hline 0.10 & 0.65 & 7.816 & 0.816 & 12.101 & 0.081 & 0.342 \\
0.15 & 0.49 & 12.747 & 0.874 & 12.040 & 0.081 & 0.520 \\
$\mathbf{0 . 2 0}$ & $\mathbf{0 . 3 7}$ & $\mathbf{1 7 . 3 3 6}$ & $\mathbf{0 . 8 9 4}$ & $\mathbf{1 1 . 9 0 0}$ & $\mathbf{0 . 0 8 2}$ & $\mathbf{0 . 6 2 1}$ \\
0.25 & 0.26 & 22.481 & 0.905 & 11.713 & 0.084 & 0.697 \\
0.30 & 0.18 & 26.872 & 0.910 & 11.492 & 0.085 & 0.743 \\
\hline
\end{tabular}

Table 4 Variable cost of care $z$ (S.3)

\begin{tabular}{lcccccc}
\hline$z\left(\alpha_{f b}, q_{f b}, p_{f b}\right)$ & $\alpha$ & $s$ & $v$ & $q$ & $p(q)$ & $P(q, s)$ \\
\hline $5.00(0.5,16.417,0.063)$ & 0.40 & 12.791 & 0.881 & 15.034 & 0.067 & 0.443 \\
$7.50(0.5,14.513,0.069)$ & 0.39 & 15.438 & 0.889 & 13.199 & 0.075 & 0.553 \\
$\mathbf{1 0 . 0}(\mathbf{0 . 5}, \mathbf{1 3 . 1 7 1}, \mathbf{0 . 0 7 5})$ & $\mathbf{0 . 3 7}$ & $\mathbf{1 7 . 3 3 6}$ & $\mathbf{0 . 8 9 4}$ & $\mathbf{1 1 . 9 0 0}$ & $\mathbf{0 . 0 8 2}$ & $\mathbf{0 . 6 2 1}$ \\
$12.5(0.5,12.137,0.081)$ & 0.35 & 19.141 & 0.899 & 10.903 & 0.090 & 0.674 \\
$15.0(0.5,11.298,0.087)$ & 0.32 & 20.045 & 0.902 & 10.086 & 0.097 & 0.706 \\
$17.5(0.5,10.591,0.092)$ & 0.30 & 19.547 & 0.902 & 9.390 & 0.104 & 0.717 \\
$20.0(0.5,9.982,0.098)$ & 0.27 & 19.865 & 0.905 & 8.800 & 0.110 & 0.736 \\
\hline
\end{tabular}


of suing; a reduction in the level of care; a rise in the probability of accident and in the probability of conviction. The fact that the first-best level of care is reduced implies that the government wants to set a lower liability share for the firm inducing a lower level of care and therefore a higher probability of accident.

\section{Case S.4: Sensitivity to changes in the efficiency of care}

The parameters are the same as in base Case (S.1) except for the parameter representing the efficiency of care in reducing the probability of accident, namely $\eta \in[0.1,0.3]$. We obtain the following in Table 5, where the first-best solution changes with the changes in parameter $\eta$.

Hence, an increased efficiency of care in reducing the probability of an accident changes the first-best values (reduced care level $q$ and a reduced probability of accident $p(q)$ ) and generates: a liability for the firm that goes up and down but a decreased standard of care; a reduction in the probability of suing; a reduction in the level of care but a reduction in the probability of accident; and a reduction in the probability of conviction. When care is more efficient, the government wants to save on costly care activities while achieving a lower probability of accident. To do so, it basically maintains the liability share of the firm but reduces the standard of care; this lowers the value of suing for the insurer. Although realized care level and probability of accident move in the same directions as their first-best values, the probability of conviction goes down as the reduction in realized care is less pronounced than the reduction in the standard of care.

\section{Case S.5: Sensitivity to changes in the cost of suing}

The parameters are the same as in Base Case (S.1) except for the parameter representing the cost for the financier of suing, that is, the cost of maintaining the necessary internal legal competencies, namely $B \in[0.5,2.5]$ (Table 6).

Hence, an increase in the cost of suing generates: an increased liability for the firm and decreased standard of care; a reduction in probability of suing; a reduction in the level of care; an increase in the probability of accident; and a reduction in the probability of conviction. Clearly, the capacity or efficiency of the insurer in inducing proper behavior by the firm is reduced when the cost of suing increases. Hence, the government will want to impose a higher liability share on the firm. To avoid a too important increase in care activities, it lowers significantly the standard of care leading to a net decrease in the level of care. But again, the reduction in realized care is less

Table 5 Variable $\eta(\mathrm{S} .4)$

\begin{tabular}{lcccccc}
\hline$\eta\left(\alpha_{F B}, q_{F B}, p_{F B}\right)$ & $\alpha$ & $s$ & $v$ & $q$ & $p(q)$ & $P(q, s)$ \\
\hline $0.10(0.5,18.709,0.104)$ & 0.32 & 44.440 & 0.937 & 16.695 & 0.116 & 0.771 \\
$0.15(0.5,15.433,0.085)$ & 0.37 & 27.524 & 0.916 & 13.916 & 0.093 & 0.704 \\
$\mathbf{0 . 2 0}(\mathbf{0 . 5}, \mathbf{1 3 . 1 7 1}, \mathbf{0 . 0 7 5})$ & $\mathbf{0 . 3 7}$ & $\mathbf{1 7 . 3 3 6}$ & $\mathbf{0 . 8 9 4}$ & $\mathbf{1 1 . 9 0 0}$ & $\mathbf{0 . 0 8 2}$ & $\mathbf{0 . 6 2 1}$ \\
$0.25(0.5,11.536,0.069)$ & 0.36 & 12.448 & 0.873 & 10.425 & 0.076 & 0.560 \\
$0.30(0.5,10.297,0.066)$ & 0.36 & 9.206 & 0.848 & 9.283 & 0.072 & 0.497 \\
\hline
\end{tabular}


The Geneva Papers on Risk and Insurance - Issues and Practice

356

Table 6 Variable $B(\mathrm{~S} .5)$

\begin{tabular}{lcccccc}
\hline$B$ & $\alpha$ & $s$ & $v$ & $q$ & $p(q)$ & $P(q, s)$ \\
\hline 0.50 & 0.30 & 24.167 & 0.934 & 12.076 & 0.081 & 0.707 \\
$\mathbf{1 . 0 0}$ & $\mathbf{0 . 3 7}$ & $\mathbf{1 7 . 3 3 6}$ & $\mathbf{0 . 8 9 4}$ & $\mathbf{1 1 . 9 0 0}$ & $\mathbf{0 . 0 8 2}$ & $\mathbf{0 . 6 2 1}$ \\
1.50 & 0.43 & 14.016 & 0.855 & 11.762 & 0.083 & 0.559 \\
2.00 & 0.49 & 11.554 & 0.810 & 11.640 & 0.084 & 0.497 \\
2.50 & 0.56 & 9.314 & 0.748 & 11.530 & 0.085 & 0.424 \\
\hline
\end{tabular}

Table 7 Variable $\lambda($ S.6)

\begin{tabular}{lcccccc}
\hline$\lambda$ & $\alpha$ & $s$ & $v$ & $q$ & $p(q)$ & $P(q, s)$ \\
\hline 0.10 & 0.77 & 7.698 & 0.758 & 11.905 & 0.082 & 0.342 \\
0.20 & 0.53 & 14.157 & 0.870 & 11.917 & 0.082 & 0.558 \\
$\mathbf{0 . 3 0}$ & $\mathbf{0 . 3 7}$ & $\mathbf{1 7 . 3 3 6}$ & $\mathbf{0 . 8 9 4}$ & $\mathbf{1 1 . 9 0 0}$ & $\mathbf{0 . 0 8 2}$ & $\mathbf{0 . 6 2 1}$ \\
0.40 & 0.22 & 20.056 & 0.908 & 11.880 & 0.083 & 0.663 \\
0.50 & 0.18 & 20.769 & 0.911 & 11.876 & 0.083 & 0.673 \\
\hline
\end{tabular}

pronounced than the reduction in the standard of care and therefore the probability of conviction is lowered.

Case S.6: Sensitivity to changes in the social cost of public funds

The parameters are same as in Base Case (S.1) except for the parameter representing the social cost of public funds, namely $\lambda \in[0.1,0.5]$ (Table 7).

Hence, an increase in the social cost of public funds (reduced efficiency of government financing) generates: a reduced liability for the firm and increased standard of care; an increase in probability of suing; an early increase and later reduction in care; an early reduction and later increase in probability of accident (the precise values are: $0.082345,0.082258$, the base case value $0.082377,0.082503$, and 0.082528 ); and an increase in the probability of conviction. Those impacts are basically due to the need for the government to reduce its own disbursements given their higher social costs. To achieve that, it lowers the liability share of the firm thereby making the compulsory insurance level higher. To avoid a too important reduction in care, the government increases also the standard of care. This induces the insurer to sue more often because of the likely higher probability of conviction.

\section{Model N (Nash)}

Case N.2: Sensitivity to changes in the profitability of the firm

The parameters are the same as in Base Case (N.1) except for the parameter representing the profitability of the firm, namely $\mu \in[0.1,0.3]$ (Table 8 ).

Hence, the reduction in profitability of the firm generates: a reduced liability for the firm and an increased standard of care; an increase in the probability of suing; a 
Table 8 Variable profitability $\mu$ (N.2)

\begin{tabular}{lcccccc}
\hline$\mu$ & $\alpha$ & $s$ & $v$ & $q$ & $p(q)$ & $P(q, s)$ \\
\hline 0.10 & 0.62 & 11.315 & 0.867 & 12.321 & 0.080 & 0.470 \\
0.15 & 0.47 & 17.179 & 0.898 & 12.201 & 0.081 & 0.611 \\
$\mathbf{0 . 2 0}$ & $\mathbf{0 . 3 6}$ & $\mathbf{2 2 . 9 1 0}$ & $\mathbf{0 . 9 1 3}$ & $\mathbf{1 2 . 0 2 7}$ & $\mathbf{0 . 0 8 2}$ & $\mathbf{0 . 6 9 5}$ \\
0.25 & 0.24 & 29.544 & 0.922 & 11.823 & 0.083 & 0.758 \\
0.30 & 0.18 & 35.213 & 0.926 & 11.598 & 0.084 & 0.796 \\
\hline
\end{tabular}

Table 9 Variable $z$ (N.3)

\begin{tabular}{lcccccr}
\hline$z\left(\alpha_{F B}, q_{F B}, p_{F B}\right)$ & $\alpha$ & $s$ & $v$ & $q$ & $p(q)$ & $P(q, s)$ \\
\hline $5.00(0.5,16.417,0.063)$ & 0.37 & 16.380 & 0.888 & 15.195 & 0.067 & 0.526 \\
$7.50(0.5,14.513,0.069)$ & 0.37 & 19.745 & 0.902 & 13.327 & 0.074 & 0.626 \\
$\mathbf{1 0 . 0}(\mathbf{0 . 5}, \mathbf{1 3 . 1 7 1}, \mathbf{0 . 0 7 5})$ & $\mathbf{0 . 3 6}$ & $\mathbf{2 2 . 9 1 0}$ & $\mathbf{0 . 9 1 3}$ & $\mathbf{1 2 . 0 2 7}$ & $\mathbf{0 . 0 8 2}$ & $\mathbf{0 . 6 9 5}$ \\
$12.5(0.5,12.137,0.081)$ & 0.34 & 25.505 & 0.920 & 11.028 & 0.089 & 0.741 \\
$15.0(0.5,11.298,0.087)$ & 0.31 & 27.061 & 0.926 & 10.215 & 0.095 & 0.770 \\
$17.5(0.5,10.591,0.092)$ & 0.29 & 27.095 & 0.930 & 9.530 & 0.102 & 0.784 \\
$20.0(0.5,9.982,0.098)$ & 0.26 & 27.230 & 0.935 & 8.942 & 0.109 & 0.796 \\
\hline
\end{tabular}

reduction in the level of care; a rise in the probability of accident and in the probability of conviction. ${ }^{36}$

Case N.3: Sensitivity to changes in the cost of care

The parameters are the same as in Base Case (N.1) except for the parameter representing the cost of care activities, namely $z \in[5,20]$. We obtain the following in Table 9, where the first-best solution changes with the changes in parameter $z$.

Hence, a higher cost of care changes the first-best values (a reduction in the level of care $q$ and therefore an increase in the probability of accident $p(q)$ ) and generates: a reduced liability for the firm and an increase in the standard of care; an increase in probability of suing; a reduction in the level of care; a rise in the probability of accident and in the probability of conviction.

Case N.4: Sensitivity to changes in the efficiency of care

The parameters are the same as in Base Case (N.1) except for the parameter representing the efficiency of care in reducing the probability of accident, namely $\eta \in[0.1,0.3]$. We obtain the following in Table 10, where the first-best solution changes with the changes in parameter $\eta$.

\footnotetext{
${ }^{36}$ Given that the intuitions are basically similar to those in the Stackelberg model, we do not explicitly repeat them here.
} 
The Geneva Papers on Risk and Insurance - Issues and Practice

358

Table 10 Variable $\eta(\mathrm{N} .4)$

\begin{tabular}{lcccccc}
\hline$\eta\left(\alpha_{F B}, q_{F B}, p_{F B}\right)$ & $\alpha$ & $s$ & $v$ & $q$ & $p(q)$ & $P(q, s)$ \\
\hline $0.10(0.5,18.709,0.104)$ & 0.24 & 51.099 & 0.938 & 16.669 & 0.116 & 0.798 \\
$0.15(0.5,15.433,0.085)$ & 0.32 & 35.515 & 0.924 & 13.978 & 0.093 & 0.761 \\
$\mathbf{0 . 2 0}(\mathbf{0 . 5}, \mathbf{1 3 . 1 7 1 , 0 . 0 7 5 )}$ & $\mathbf{0 . 3 6}$ & $\mathbf{2 2 . 9 1 0}$ & $\mathbf{0 . 9 1 3}$ & $\mathbf{1 2 . 0 2 7}$ & $\mathbf{0 . 0 8 2}$ & $\mathbf{0 . 6 9 5}$ \\
$0.25(0.5,11.536,0.069)$ & 0.37 & 16.197 & 0.904 & 10.592 & 0.075 & 0.636 \\
$0.30(0.5,10.297,0.066)$ & 0.37 & 11.997 & 0.895 & 9.492 & 0.070 & 0.578 \\
\hline
\end{tabular}

Table 11 Variable $B($ N.5)

\begin{tabular}{lcccccc}
\hline$B$ & $\alpha$ & $s$ & $v$ & $q$ & $p(q)$ & $P(q, s)$ \\
\hline 0.50 & 0.27 & 28.523 & 0.943 & 12.127 & 0.081 & 0.745 \\
$\mathbf{1 . 0 0}$ & $\mathbf{0 . 3 6}$ & $\mathbf{2 2 . 9 1 0}$ & $\mathbf{0 . 9 1 3}$ & $\mathbf{1 2 . 0 2 7}$ & $\mathbf{0 . 0 8 2}$ & $\mathbf{0 . 6 9 5}$ \\
1.50 & 0.43 & 19.590 & 0.883 & 11.959 & 0.082 & 0.655 \\
2.00 & 0.50 & 16.839 & 0.851 & 11.907 & 0.082 & 0.613 \\
2.50 & 0.62 & 12.975 & 0.797 & 11.862 & 0.083 & 0.531 \\
\hline
\end{tabular}

Hence, an increase in the efficiency of care in reducing the probability of accident changes the first-best values (a reduction in the level of care $q$ and a reduction in the probability of accident $p(q)$ ) and generates: an increased liability for the firm and a decreased standard for care; a reduction in probability of suing; a reduction in the level of care but a reduction in the probability of accident; and a reduction in the probability of conviction.

Case N.5: Sensitivity to changes in the cost of suing

Parameters are the same as in Base Case (N.1) except for the parameter representing the cost for the financier of suing, that is, the cost of maintaining the necessary internal legal competencies, namely $B \in[0.5,2.5]$ (Table 11 ).

Hence, an increase in the cost of suing generates: an increased liability for the firm and a decreased standard of care; a reduction in the probability of suing; a reduction in the level of care; an increase in the probability of accident; and a reduction in the probability of conviction.

Case N.6: Sensitivity to changes in the social cost of public funds

Parameters are the same as in Case N.1 except for the parameter representing the social cost of public funds, namely $\lambda \in[0.1,0.5]$ (Table 12).

Hence, an increase in the social cost of public funds (reduced efficiency of government financing either through taxation of public debt) generates: a reduced liability for the firm and an increased standard for care; an increase in the probability of suing; a reduction in the level of care; an increase in the probability of accident and in the probability of conviction. 
Table 12 Variable $\lambda$ (N.6)

\begin{tabular}{lcccccc}
\hline$\lambda$ & $\alpha$ & $s$ & $v$ & $q$ & $p(q)$ & $P(q, s)$ \\
\hline 0.1 & 0.74 & 11.910 & 0.835 & 12.064 & 0.081 & 0.496 \\
0.2 & 0.52 & 19.104 & 0.894 & 12.050 & 0.081 & 0.646 \\
$\mathbf{0 . 3}$ & $\mathbf{0 . 3 6}$ & $\mathbf{2 2 . 9 1 0}$ & $\mathbf{0 . 9 1 3}$ & $\mathbf{1 2 . 0 2 7}$ & $\mathbf{0 . 0 8 2}$ & $\mathbf{0 . 6 9 5}$ \\
0.4 & 0.20 & 25.780 & 0.924 & 12.003 & 0.082 & 0.724 \\
0.5 & 0.18 & 26.137 & 0.925 & 11.999 & 0.082 & 0.727 \\
\hline
\end{tabular}

\section{Conclusion}

The importance of the role of the insurance industry in the environmental realm stems from the accelerating diffusion of environmentally risky production activities in modern industrial societies and the ensuing necessity to properly compensate the victims of accidents. The challenging attempt by EC countries to involve insurance companies in the European environmental protection system either through traditional liability policies or financial responsibility instruments, reviewed in the first part of the paper, is also connected with the need to induce an efficient level of care by the firms in contexts characterized by asymmetric information and partial control.

In this paper, we presented a structural model of the interactions between governments, firms, courts and insurance companies as financial institutions, characterizing the liability sharing formula between insurance companies and firms and the imperfect implementation of government policies.

The model is based on a form of "extended principal-agent liability," under which financial institutions have an incentive to properly identify and monitor risky firms. Contrary to what the law and economics literature usually do, we looked at the legislator's point of view, which here is to determine what shares of liability to impose on the principal and the agent in order to maximize the social welfare function. By sharing liability between firms and financial institutions, the legislator delegates part of its control upon the firm's preventive behavior.

We also considered that the principal-agent relationship between the insurance company and the firm is only part of the complex network of relationships. Other important actors were included in the model, such as government and court, because they play an important role in shaping the incentive system for preventive environmental care.

The main contribution of the paper is in the sensitivity analysis of changes in profitability, cost and efficiency of care, cost of suing, and social cost of public funds on the social welfare maximizing liability sharing formula and standard of care.

To summarize the results, we can say that in the Stackelberg (with the insurer as leader and the firm as follower) equilibrium with asymmetric information, the liability share of the firm is lower than in the first-best solution. Moreover, the firm exerts less care in preventing accident and therefore the probability of accident increases. Starting from a base case scenario, we characterized the effects of changes in the profitability of the firm, the cost and efficiency of care, the cost of suing, and the cost of public funds. 
360

A reduction in the profitability or a higher cost of care for the firm imply a reduced liability for the firm and an increased (not always in the second case) standard of care, an increase in the probability of suing, a reduction in the level of care, a rise in the probability of accident and in the probability of conviction. An increased efficiency of care implies a liability for the firm that goes up and down but a decreased standard of care and a reduction in the probability of suing, in the level of care but nevertheless a reduction in the probability of accident, and a reduction in the probability of conviction. An increase in the cost of suing implies an increased liability for the firm and a decreased standard of care, a reduction in probability of suing, a reduction in the level of care, an increase in the probability of accident, a reduction in the probability of conviction. Finally, an increase in the social cost of public funds implies a reduced liability for the firm and an increased standard of care, an increase in probability of suing, an early increase and later reduction in care, an early reduction and later increase in probability of accident, an increase in the probability of conviction. We provided the intuitions for these results.

In the second part of the sensitivity analysis, we found that in the Nash equilibrium with asymmetric information, compared with the Stackelberg equilibrium, we obtain a similar liability sharing but a higher standard for care, a higher probability of suing, a higher level of care and therefore a lower probability of accident, and a higher probability of conviction. Starting from a base case scenario, we similarly characterized the effects of changes in the profitability of the firm, the cost and efficiency of care, the cost of suing, and the cost of public funds. A reduction in profitability or a higher cost of care for the firm imply a reduced liability for the firm and an increased standard of care, an increase in the probability of suing, a reduction in the level of care, a rise in the probability of accident and in the probability of conviction. An increase in the efficiency of care implies an increased liability for the firm and a decreased standard for care, a reduction in probability of suing, in the level of care but nevertheless a reduction in the probability of accident, and a reduction in the probability of conviction. The results are the same for an increase in the cost of suing, except for an increase in the probability of accident. An increase in the social cost of public funds implies a reduced liability for the firm and an increased standard for care, an increase in the probability of suing, a reduction in the level of care, and an increase in the probability of accident and in the probability of conviction.

Our model, considering different actors, namely governments, firms, insurance companies and courts, involves a set of complex interactions between them in the determination of environmental accidents. The modeling strategy we followed cannot admittedly give direct and simple results but we tried to make explicit the interactions between the four players, in order to capture many, if not all, the important characteristics, stemming from institutional and informational constraints, of a large number of real situations.

In particular, we think that it is important to better understand the underlying factors of an efficient liability sharing factor by which national governments or EU institutions could delegate in part the monitoring of the safety behavior of environmentally risky firms. We hope that characterizing such liability sharing factor will contribute to the general debate about the design of an optimal environmental policy. 
Marcel Boyer and Donatella Porrini Efficient Liability Sharing Factor for Environmental Disasters

\section{References}

Abraham, K.S. (1988) 'Environmental liability and the limits of insurance', Columbia Law Review 88: 942-988.

Baumol, W.J. and Oates, W. (1988) The Theory of Environmental Policy, 2nd edn, Cambridge, UK: Cambridge University Press.

Boyd, J. (2002) 'Financial responsibility for environmental obligations: An analysis of environmental bonding and assurance rules', in T. Swanson (ed) Law and Economics of Environmental Policy (Research in Law and Economics), Amsterdam: Elsevier Science.

Boyd, J. (2003) 'A market-based analysis of financial assurance issues associated with U.S. natural resource damage liability', in M. Faure (ed) Tort and Insurance Law, vol. 5, Deterrence, Insurability and Compensation in Environmental Liability, Future Developments in the European Union, New York: Springer.

Boyer, M. and Laffont, J.J. (1996) 'Environmental protection, producer insolvency and lender liability', in A. Xepapadeas (ed) Economic Policy for the Environment and Natural Resources, Chapter 1, Cheltenham, UK: Edward Elgar Publishing Ltd.

Boyer, M. and Laffont, J.J. (1997) 'Environmental risks and bank liability', European Economic Review 41: 1427-1459.

Boyer, M. and Porrini, D. (2001) 'Law versus regulation: A political economy model of instruments choice in environmental policy', in A. Heyes (ed) Law and Economics of the Environment, Cheltenham, UK: Edward Elgar Publishing Ltd.

Boyer, M. and Porrini, D. (2002) 'The choice of instruments for environmental policy: Liability or regulation?', in T. Swanson and R. Zerbe (eds) An Introduction to the Law and Economics of Environmental Policy: Issues in Institutional Design (Research in Law and Economics Series, Vol. 20), Amsterdam: Elsevier Science Ltd., pp. 245-268.

Boyer, M. and Porrini, D. (2004) 'Modeling the choice between regulation and liability in terms of social welfare', Canadian Journal of Economics 37: 590-612.

Boyer, M. and Porrini, D. (2006) 'Sharing liability between banks and firms: The case of industrial safety risk', in M. Boyer, Y. Hiriart and D. Martimort (eds) Frontiers in the Economics of Environmental Regulation and Liability, London: Ashgate Publishing, Chapter 13, pp. 311-341.

Boyer, M. and Porrini, D. (2008) Court efficiency and liability sharing under asymmetric information, mimeo. Calabresi, G. (1970) The Cost of Accident, New Haven: Yale University Press.

COM (2000) White Paper on Environmental Liability, 66 final, Brussels, European Commission, February 9.

Cropper, M.L. and Oates, W.E. (1992) 'Environmental economics: A survey', Journal of Economic Literature XXX: 1675-1740.

Daughety, A.F. and Reinganum, J.F. (2003) Markets, torts and social inefficiency, Vanderbilt Law and Economics Research Papers No. 03-07, Vanderbilt University.

European Parliament and Council (2004) 'Directive 2004/35/CE of the European Parliament and of The Council of 21 April 2004 on environmental liability with regard to the prevention and remedying of environmental damage', Official Journal of the European Union, L143/56, 30/4/04.

Faure, M. and Grimeaud, D. (2000) Financial Assurance Issues of Environmental Liability, Report for the European Commission, from http:/www.europa.eu.int/comm/environment/liabilitylinsurance_gen.htm.

Faure, M. and Skogh, G. (1992) 'Compensation for damages caused by nuclear accidents: A convention as insurance', The Geneva Papers on Risk and Insurance - Issues and Practice 17: 499-513.

Feess, E. and Hege, U. (2000) 'Environmental harm, and financial responsibility', The Geneva Papers of Risk and Insurance - Issues and Practice 25: 220-234.

Freeman, P. and Kunreuther, H. (1997) Managing Environmental Risk Through Insurance, Washington, DC: American Enterprise Institute.

Heyes, A. (1996) 'Lender penalty for environmental damage and the equilibrium cost of capital', Economica 63: $311-323$.

Kornhauser, L.A. (1982) 'An economic analysis of the choice between enterprise and personal liability for accidents', California Law Review 70: 1345-1392.

Laffont, J.J. and Martimort, D. (2001) The Theory of Incentives: The Principal-Agent Model, Princeton, NJ: Princeton University Press. 
Monti, A. (2001) 'Environmental risk: A comparative law and economics approach to liability and insurance', European Review of Private Law 1: 51-79.

Pitchford, R. (1995) 'How liable should a lender be?', American Economic Review 85: 1171-1186.

Polinsky, M.A. (2003) Principal-agent liability, Stanford University Law School Working Paper, n. 258, Stanford University.

Priest, G. (1987) 'The current insurance crisis and Modern Tort law', Yale Law Journal 96: 1521-1590.

Ringleb, A.H. and Wiggins, S.N. (1990) 'Liability and large-scale, long-term hazards', Journal of Political Economy 98: 574-595.

Segerson, K. and Tietenberg, T. (1992) 'The structure of penalties in environmental enforcement: an economic analysis', Journal of Environmental Economics and Management 23: 179-200.

Shavell, S. (1986) 'The judgement proof problem', International Review of Law and Economics 6: 45-58.

Shavell, S. (1987) Economic Analysis of Accident Law, Cambridge, MA: Harvard University Press.

Shavell, S. (2003) Foundations of Economic Analysis of Law, Cambridge, MA: Harvard University Press.

Stone McGuigan, J. (2000) The Potential Economic Impact of Environmental Liability: The American and European Contexts, Economic Analysis Unit Environment Directorate, European Commission, December.

Sykes, A.O. (1984) 'The economics of vicarious liability', The Yale Law Journal 93: 1231-1280.

Tyran, J.R. and Zweifel, P. (1993) 'Environmental risk internalisation through capital markets (ERICAM): The case of nuclear power', International Review of Law and Economics 13: 431-444.

\section{About the Authors}

Marcel Boyer (Ph.D. economics, Carnegie-Mellon University) is Bell Canada Professor of industrial economics at the Université de Montréal and Vice-president and Chief economist at the Montreal Economic Institute. Author or coauthor of over 200 scientific articles, public reports and scientific papers, Professor Boyer currently conducts research in the areas of investment valuation (risk, flexibility and real options); efficient organizations, innovation and competition (competitive social democracy); incentives, incomplete information and uncertainty; and law and economics (environmental issues, copyrights, IPR), organizations and tribunals (http://www.cirano.qc.ca/cv.php?lang = en\&coderelation =1107).

Donatella Porrini is Associate Professor in Economics, University of Lecce since 2004. She is the author of research in law and economics, particularly related to insurance and bank markets regulatory issues. She is the author also of articles about the economic analysis of responsibility for environmental damage (http://www. donatellaporrini.it/). 